\title{
Mercury cycling between the water column and surface sediments in a contaminated area
}

\author{
Elsa Ramalhosa ${ }^{a, *}$, Susana Río Segade ${ }^{b}$, Eduarda Pereira $^{c}$, Carlos Vale $^{d}$, Armando Duarte $^{c}$ \\ ${ }^{a}$ CIMO, Escola Superior Agrária de Bragança, Instituto Politécnico de Bragança, 5300 Bragança, Portugal \\ ${ }^{\mathrm{b}}$ Estación de Viticultura e Enoloxía de Galicia (EVEGA), Ponte San Clodio s/n, Leiro, 32427-Ourense, Spain \\ ${ }^{\mathrm{C}}$ Departamento de Química, Universidade de Aveiro, 3810-193 Aveiro, Portugal \\ ${ }^{\mathrm{d}}$ Instituto de Investigação das Pescas e do Mar (IPIMAR), Av. Brasília, 1400 Lisboa, Portugal
}

\section{A R T I C L E I N F O}

Article history:

Received 29 March 2004

Received in revised form

9 May 2006

Accepted 19 May 2006

Available online 18 July 2006

Keywords:

Reactive mercury

Non-reactive mercury

Sediments

Pore waters

Diffusion

Largo do Laranjo

\begin{abstract}
A B S T R A C T
Mercury cycling in the water column and upper sediments of a contaminated area, the Largo do Laranjo, Aveiro (Portugal), was evaluated after determination of reactive and nonreactive mercury concentrations in the water column and pore waters of sediments, collected in several places of this bay. In the water column, reactive mercury concentrations varied between 10 and $37 \mathrm{pmol} \mathrm{dm}^{-3}$, the highest values being observed near the mercury anthropogenic source. However, reactive mercury was a narrowly constrained fraction of the total mercury, making up only $4-16 \%$ of the total, showing evidence of the importance of dissolved organic matter on mercury transport.

In sediments, higher concentrations of mercury were also determined near industrial discharges. Results indicate the existence of an equilibrium between solid and liquid phases, determined by solid sediment/pore water distribution coefficients. Much of the mercury present in the solid fraction is associated with organic matter $(r=0.837)$ and iron oxyhydroxides $(r=0.919)$, but as oxides begin to dissolve in reduced sediments and organic matter decays, the adsorbed mercury is released. In fact, the mercury concentrations in pore waters of those contaminated sediments largely exceeded the values determined in the water column. As molecular diffusion may contribute to the dissolved mercury distribution in the overlying water column, this phenomenon was evaluated. However, the pore waters of Largo do Laranjo do not enrich the water column substantially in terms of reactive and non-reactive mercury. In fact, pore waters can contribute only to $0.2 \%$ and $0.5 \%$ of the reactive and non-reactive mercury present in the water column, respectively, showing that as long as mercury is being incorporated in sediments, it stays in stable forms.
\end{abstract}

(c) 2006 Elsevier Ltd. All rights reserved.

\section{Introduction}

The fate and reactivity of anthropogenic mercury in the aquatic environment are of major concern owing to their toxicity for most organisms and humans. Trace metals are particle reactive (Paraquetti et al., 2004) and quickly sorbed to the suspended particulate matter (SPM) (Kennish, 1998) or to the particulates in the sediment-water interface. Once they reach the sediment, the major fraction of anthropogenic mercury is ultimately retained (Kennish, 1998). In many situations, the vertical profiles of total mercury in sediments record the historical contamination of the area under study

*Corresponding author. Tel.: +351273 303 262; fax: +351273325405.

E-mail address: elsa@ipb.pt (E. Ramalhosa).

0043-1354/\$ - see front matter (c) 2006 Elsevier Ltd. All rights reserved.

doi:10.1016/j.watres.2006.05.023 
(Kennish, 1998; Bellucci et al., 2002). However, the coastal sediments are highly dynamic and the conditions existing in the upper layers influence the sediment-water exchanges and have a strong effect on the distribution of trace elements (Sundby, 1994). The remobilisation due to the resuspension of metal enriched on fine bed sediments may increase the dissolved metal content in the overlying water column (Martino et al., 2002), as well as maintain large amounts of particulate mercury (Lacerda and Gonçalves, 2001). The types and the extension of the reactions that take place between the solid sediments and the aqueous phase can be evaluated by the pore water composition (Hong et al., 1994). This may be enriched in mercury in comparison to the water column (Cossa and Gobeil, 2000). This mercury present in the pore waters may escape to the water column and deleteriously affect the biota.

Since decades, a chlor-alkali plant has been discharging mercury into one of the most remote branches of Ria de Aveiro, which is a coastal lagoon with a permanent connection to the sea. Most of the discharged mercury settles in Largo do Laranjo, an inner bay of $1.5 \mathrm{~km}^{2}$. Since the $1980 \mathrm{~s}$, high mercury concentrations in sediments, SPM and water have been detected and reported in several studies (Lucas et al., 1986, Pereira et al., 1998ab, Ramalhosa et al., 2001a). Generally, the highest mercury concentrations in sediments (maximum $35 \mu \mathrm{gg}^{-1}$ ) were found at $30-40 \mathrm{~cm}$ depth, corre- sponding to the period of maximum industrial production (Pereira et al., 1998a). However, particulate mercury escapes when the surface sediments are resuspended and transported by the tide to the rest of the lagoon (Pereira et al., 1998b). The contribution of the dissolved mercury was not evaluated due to the low concentrations found (Pereira et al., 1998b). In posterior works, the pore water profiles indicated that mercury is being remobilised in the anoxic sediments and these may constitute internal sources of mercury to the water column (Ramalhosa et al., 2001a).

This study presents the distributions of total and reactive mercury in solid sediments, pore waters and water column, as well as iron and organic matter, in Largo do Laranjo. On the basis of these data, associations of mercury in sediments and water column are evaluated and mercury cycling between both compartments is assessed by considering molecular diffusion.

\section{Materials and methods}

\subsection{Sampling}

Surface sediments $(0-0.5 \mathrm{~cm}$ layers) were collected with a grab sampler at 20 sites in Largo do Laranjo contaminated area in February 2000 (Fig. 1). The fluvial flow rate was high in this

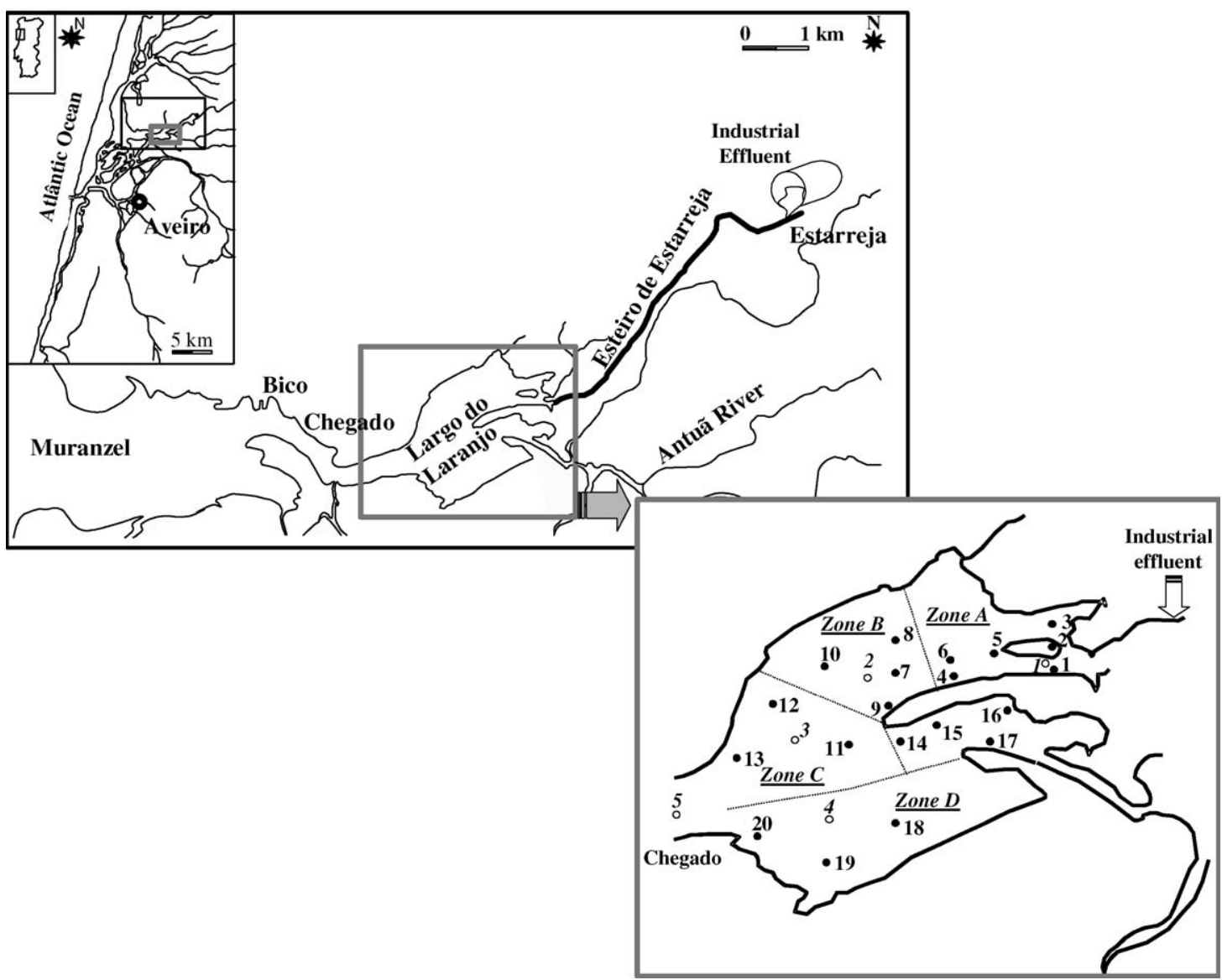

Fig. 1 - Detailed maps of Ria de Aveiro and Largo do Laranjo, showing the location of the sediment $(\bullet)$ and water $(\bigcirc)$ sampling stations. The mercury industrial discharge is also marked. 
month due to rainfall and to the deviation of a significant part of Antuã River flow rate to Esteiro de Estarreja, originating high volumes of circulating water. The water samples were collected at five sites $(1,2,3,4$ and 5) by hand, using polyethylene gloves and glass bottles of $500 \mathrm{~cm}^{3}$, during low and high tides. All material was previously acid cleaned, following the procedure of Diego et al. (1998). The samples were kept refrigerated and immediately transported to the laboratory.

\subsection{Measurements in loco}

Several measurements were performed in loco. In the water column, temperature, salinity (WTW, LF 196), pH (Orion, model $720 \mathrm{~A}$ ) and dissolved oxygen (WTW, Oxi 96A) were measured. On the other hand, $\mathrm{pH}$ (WTW, model 320) and redox potential (Mettler Pt 4805/S7, with an Ag/AgCl reference electrode) were determined in the surface sediments.

\subsection{Sample treatment}

All sediment samples were treated in a nitrogen-filled glove bag to prevent oxidation reactions. The pore water samples were extracted from sediments by centrifugation at $6000 \mathrm{rpm}$ for $20 \mathrm{~min}$ (B. Braun, model Sigma 4-10). A portion of the supernatant liquid was filtered through Millipore $0.45 \mu \mathrm{m}$ porosity filters. The filtrate was collected in acid-cleaned bottles, preserved by acidification to $\mathrm{pH}<2$ with nitric acid (mercury free) and placed at $4{ }^{\circ} \mathrm{C}$. Another portion of the supernatant liquid was filtered through Gelman glass fibre filters to evaluate the dissolved organic matter. Previously, the filters were cleaned by heating at $450^{\circ} \mathrm{C}$ for $24 \mathrm{~h}$. All the water samples were treated in the same way as the pore waters. Identical volumes of ultrapure water were carried through the centrifugation and filtration stages as a blank procedure. Portions of all sediments were freeze dried (Christ, model Alpha 1-4), homogenised and sieved through $1 \mathrm{~mm}$ and $63 \mu \mathrm{m}$ stainless-steel sieves (Fritsch, model Analysette 3).

\subsection{Mercury and organic matter determinations in the pore waters and water column dissolved fraction}

Both filtered waters were analysed for reactive mercury by cold vapour atomic fluorescence spectrometry (PSA cold vapour generator, model 10.003, associated with a Merlin PSA detector, model 10.023), using $\mathrm{SnCl}_{2}$ as a reducing agent. This mercury fraction includes mostly ionic $\left(\mathrm{Hg}^{2+}\right)$ plus dissolved gaseous mercury, but also one that is weakly bound to inorganic and organic dissolved complexes (Fitzgerald and Mason, 1997). The dissolved mercury detection limit was calculated from 44 calibration curves in the concentration range $10-100 \mathrm{pmol} \mathrm{dm}^{-3}$, varying from 1.1 to $8.9 \mathrm{pmol} \mathrm{dm}^{-3}$. The detection limit was calculated as the intercept plus three times the standard deviation of the signal. The relative standard deviation $(n=5)$ for a $100 \mathrm{pmol} \mathrm{dm}^{-3}$ inorganic mercury standard was less than $5 \%$. No peak was detected when the blanks were analysed. The total dissolved mercury concentrations were determined after oxidation with potassium persulphate and ultraviolet radiation, as described by Mucci et al. (1995). Non-reactive mercury was determined by the difference between total dissolved mercury and reactive mercury, and included all dissolved mercury species strongly bound to soluble complexes (Gill and Bruland, 1990). The dissolved organic matter concentration was determined using persulphate/ultraviolet oxidation.

\subsection{Mercury, iron and organic matter determinations in the solid fraction of sediments and SPM}

The sediments solid fraction was analysed for total mercury, methylmercury, organic matter and hydroxylamine-extractable iron. The total mercury concentrations were determined following the acid digestion procedure reported by Pereira et al. (1998a). The accuracy and precision of the method were evaluated using an estuarine-certified reference material (BCR 277). The determined value $1.73 \pm 0.03 \mu \mathrm{gg}^{-1}$ (mean \pm confidence limit at $\alpha=0.05 ; n=10$ ) was in good agreement (t-test and $F$-test at $\alpha=0.05$ ) with the certified value of $1.77 \pm 0.06 \mu \mathrm{gg}^{-1}$ (mean \pm confidence limit at $\alpha=0.05$ ). Methylmercury concentration was determined by the procedure described by Ramalhosa et al. (2001b). Briefly, the methylmercury extraction from sediments is based on a microwaveassisted alkaline digestion with methanolic potassium hydroxide $\left(0.15 \mathrm{~g}\right.$ of sediment was suspended into $6 \mathrm{~cm}^{3}$ of $25 \%$ methanolic potassium hydroxide and the slurry was exposed to microwave irradiation at $84 \mathrm{~W}$ for $2 \mathrm{~min}$ ). Organomercury species were extracted with dichloromethane in hydrochloric acid medium and back-extracted into ultrapure water. The sediment extracts were injected into an analytical system composed of high-performance liquid chromatography-ultraviolet post-column oxidation-cold vapour atomic fluorescence spectrometry (HPLC-UV-PCO-CV-AFS). The detection limit of this method was $12 \mathrm{ng} \mathrm{g}^{-1}$, calculated as the intercept plus three times the standard deviation of the signal. Two sediment reference materials (BCR 580 and IAEA 356), containing different amounts of methylmercury, were analysed to evaluate the accuracy and precision of the method. The analysis of samples with low methylmercury contents required the treatment of several $0.15 \mathrm{~g}$ portions and mixing of the dichloromethane extracts obtained for each portion. The determined methylmercury concentrations in both reference materials (BCR 580: $69.5 \pm 8.8 \mathrm{ngg}^{-1}$; IAEA 356: $5.53 \pm 0.21 \mathrm{ngg}^{-1}$; mean \pm confidence limit at $\alpha=0.05, n=3$ for each) were in good agreement (t-test and F-test at $\alpha=0.05$ ) with the certified values (BCR 580: $75.5 \pm 3.7 \mathrm{ngg}^{-1}$; IAEA 356: $5.46 \pm 0.39 \mathrm{ngg}^{-1}$; mean \pm confidence limit at $\left.\alpha=0.05\right)$. The organic matter in sediments was determined by elemental analysis (LECO, model CHNS-392). Iron oxyhydroxides were determined after extraction with hydroxylamine: $0.5 \mathrm{~g}$ of sediment was treated with $20 \mathrm{~cm}^{3}$ of $0.1 \mathrm{~mol} \mathrm{dm} \mathrm{m}^{-3}$ hydroxylamine solution at $\mathrm{pH} 2$ (obtained by adding acetic acid) for $16 \mathrm{~h}$. The suspension was filtered through Millipore $0.45 \mu \mathrm{m}$ porosity filters and the filtrate was analysed for iron by flame atomic absorption spectrometry (Perkin Elmer, Aanalyst 100).

SPM was analysed for total mercury and particulate organic carbon (POC). The total mercury concentrations were determined following the procedure described for the sediments solid fraction. POC was determined after potassium dichromate oxidation in presence of sulphuric acid, as suggested by Kramer et al. (1994). 


\section{Results}

\subsection{Water column}

During the surveys, the Largo do Laranjo water column was oxygenated (51-96\% saturation) with $\mathrm{pH}$ values smaller at low tide $(7.3 \pm 0.0)$ than at high tide $(7.6 \pm 0.1)$, and statistically $(\alpha=0.05)$ higher dissolved organic carbon concentrations at low tide $\left(222 \pm 21 \mu \mathrm{mol} \mathrm{dm}{ }^{-3}\right)$ than at high tide $(170 \pm$ $\left.19 \mu \mathrm{mol} \mathrm{dm}{ }^{-3}\right)$. The reactive mercury concentrations varied between 10 and $37 \mathrm{pmol} \mathrm{dm}^{-3}$, accounting for $4-16 \%$ of total dissolved mercury. At low tide, enhanced reactive mercury contents were found at sites 1, 2 and 3, located close to the industrial effluent. At site 4, similar reactive mercury concentrations were observed at low and high tides, and higher concentrations were observed at site 5 at high tide than at low tide.

In the particulate fraction, SPM showed a similar trend at both tidal conditions, varying in the concentration range $37+14 \mathrm{mg} \mathrm{dm}^{-3}$, as shown in Fig. 2. However, SPM concentration decreased significantly only at low tide, in the farthest place from industrial effluent (site 5). POC showed a different behaviour in comparison with SPM. At low tide, POC concentrations varied slightly $(5.4+0.3 \%)$, while they decreased along Largo do Laranjo towards the sea $(5.3+1.4 \%)$ at high tide, again with exception of site 5 . In terms of total particulate mercury, the highest concentrations were determined at low tide, decreasing from 95 to $19 \mathrm{nmolg}^{-1}$ along estuary. At high tide, the total mercury concentrations varied between 8 and $23 \mathrm{nmol} \mathrm{g}^{-1}$.

\subsection{Sediments}

The proportion of fine particles $(<63 \mu \mathrm{m})$, present in the collected sediments, varied between $8 \%$ and $61 \%$ in the vicinity of the industrial discharge. The $\mathrm{pH}$ of the surface sediments ranged between 6.4 and 7.0, decreasing in the sites closest to the effluent. The redox potential irregularly ranged between 8 and $292 \mathrm{mV}$. The organic carbon content and the hydroxylamine extractable iron in the sediments varied within broad ranges, $0.13-4.6 \mathrm{mmol} \mathrm{g}^{-1}$ and $5.2-50 \mu \mathrm{mol} \mathrm{g}^{-1}$, respectively. The lowest values were found in the samples where sand was visually detected. The organic matter content is linearly correlated $\left(r^{2}=0.62\right)$ with the proportion of fine particles.

The spatial distribution of total mercury concentrations in sediments is presented in Fig. 3. The highest concentrations $\left(>70 \mathrm{nmol} \mathrm{g}^{-1}\right)$ were recorded in the sediments deposited near the industrial discharge and the lowest values (minimum of $0.73 \mathrm{nmolg}^{-1}$ ) were found in the sands of the bay outlet. The total mercury distribution is exponentially related with the fine fraction of the sediments $\left(r^{2}=0.616\right)$. Methylmercury was detected only in the sites closest to the industrial discharge ( $61 \mathrm{pmolg}^{-1},<0.1 \%$ of total mercury). The reactive mercury concentrations were higher in the pore waters surface sediments $\left(17-188 \mathrm{pmol} \mathrm{dm}^{-3}\right)$ than in the water column (10-37 pmol $\left.\mathrm{dm}^{-3}\right)$. Reactive mercury accounts for $3.7-21 \%$ of the total dissolved mercury present in the pore waters.

\section{Discussion}

\subsection{Mercury in water column}

In Largo do Laranjo, the highest reactive mercury concentrations were found near the industrial discharge and at low tide, due to lower flow rates and the smaller seawater contribution. However, exceptions were observed (site 5), where the highest concentrations corresponded to the high tide, probably due to a higher resuspension of surface sediments originated by the highest flow rates, increasing the SPM from 22 to $45 \mathrm{mg} \mathrm{dm}^{-3}$. This resuspension can induce the transfer of mercury associated with the particles to the water column dissolved phase by competition of chloride ions for mercury and/or desorption of mercury from particle's surface because of magnesium ions present in seawater.

Reactive mercury represents a small fraction (4-16\%) of total dissolved mercury, suggesting that the majority of total dissolved mercury is strongly bound to dissolved organic complexes. At low tide, when the dissolved organic carbon content was higher, similar patterns of dissolved organic carbon, total mercury and reactive mercury were observed, as stated in Fig. 4, indicating the importance of this component on mercury transport. However, this role is less pronounced

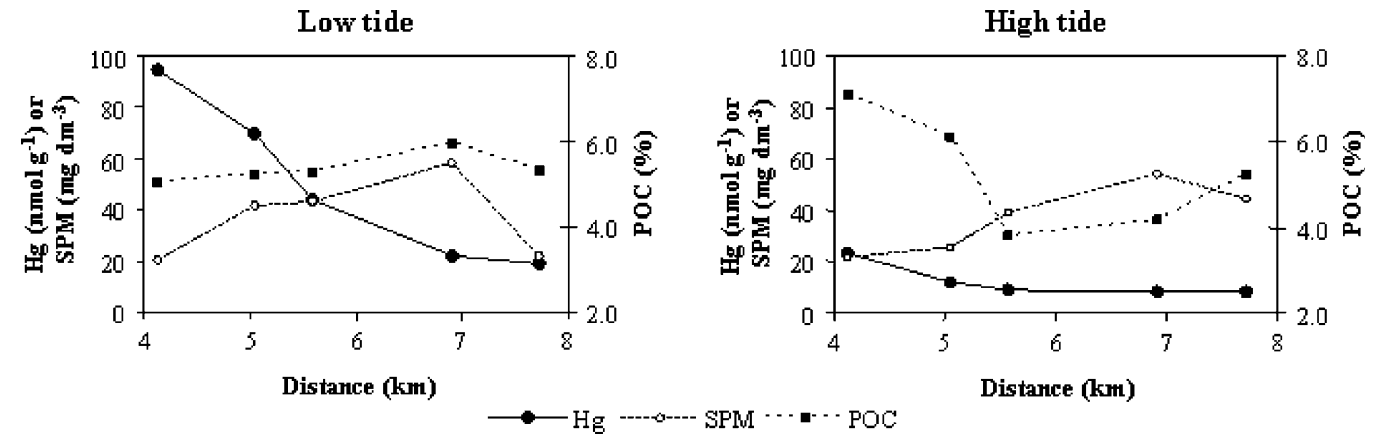

Fig. 2 - Total particulate mercury $\left(\mathrm{nmol} \mathrm{g}^{-1}\right), \mathrm{SPM}\left(\mathrm{mg} \mathrm{dm}^{-3}\right)$ and POC (\%) distributions as a function of distance to the mercury source, for low and high tides. 


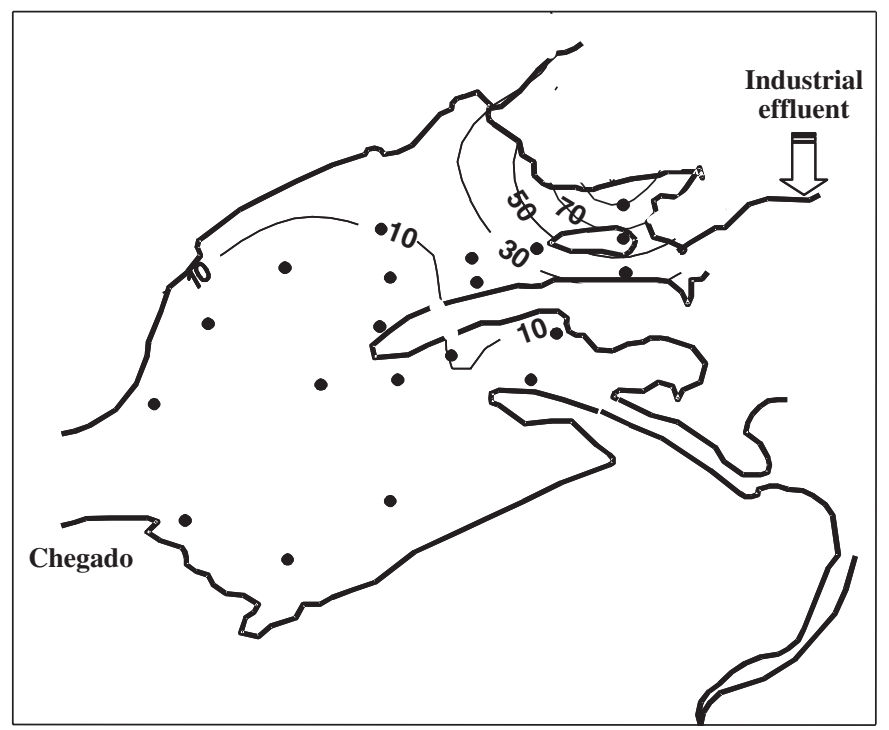

Fig. 3 - Total mercury concentration isoline $\left(\mathrm{nmol} \mathrm{g}^{-1}\right)$ distribution in regard to the surface sediments solid phase, collected in Ria de Aveiro in February 2000. The sampling locations ( $(\bullet)$ are also represented.
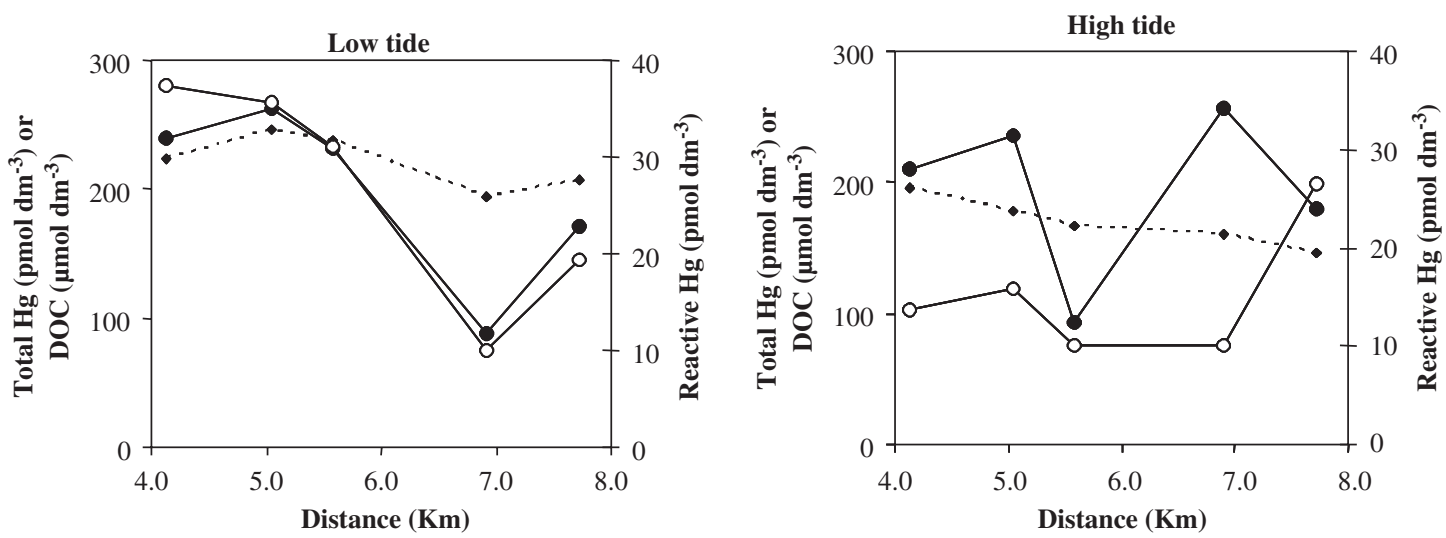

..... DOC $\longrightarrow$ Total $\mathrm{Hg} \longrightarrow$ - Reactive $\mathrm{Hg}$

Fig. 4 - Distributions of the total and reactive mercury concentrations (pmol dm${ }^{-3}$ ) determined in the water column dissolved fraction, as well as the dissolved organic carbon content $\left(\mu \mathrm{mol} \mathrm{dm}{ }^{-3}\right)$, as a function of distance to the mercury source, for low and high tides.

at high tide, probably due to the lower dissolved organic carbon concentrations and higher flow rates that alter the existent equilibriums.

In the particulate phase of the water column, total mercury did not show any significant relationship with SPM or POC.

In order to evaluate the contributions of the dissolved and particulate phases on mercury behaviour, distribution coefficients $\left(K_{\mathrm{D}}\right)$ were calculated for both tidal conditions. At low tide, $K_{D}$ values were higher than at high tide, indicating that $71-94 \%$ of total mercury is associated with particles. At high tide, total mercury was less associated with particles (56-80\%), showing that sometimes the dissolved phase is also an important vehicle for mercury. This situation can be more deleterious for biota and must be taken into account when ways of action have to be decided to resolve the mercury contamination problem in Largo do Laranjo.

\subsection{Mercury in sediments}

The surface sediments collected in this study presented mercury concentrations comparable to the values recorded in a previous work (Pereira et al., 1998a). In the present study, the highest mercury contents were found in the area near the industrial discharge and were positively correlated to both the organic carbon $(r=0.837)$ and the iron oxyhydroxides $(r=0.919)$ contents. The organic carbon present in Largo do Laranjo sediments may result from industrial effluents and also from the decomposition of extensive algae coverage and plankton inside the bay, as stated by Monterroso et al. (2003). The triangular representation of total mercury, iron and organic carbon concentrations shows that mercury is more closely associated with iron oxides than with organic matter (Fig. 5). Although it is expected that mercury is strongly linked 


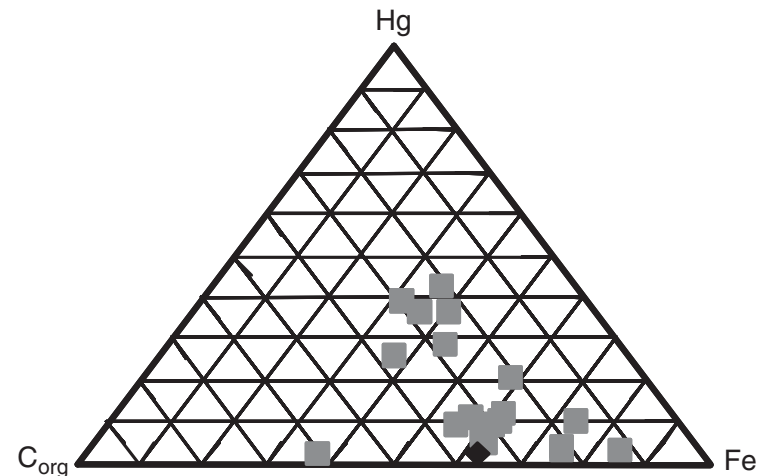

Fig. 5 - Triangular representation of the total mercury, iron and organic matter present in the solid phase of surface sediments collected from Largo do Laranjo.

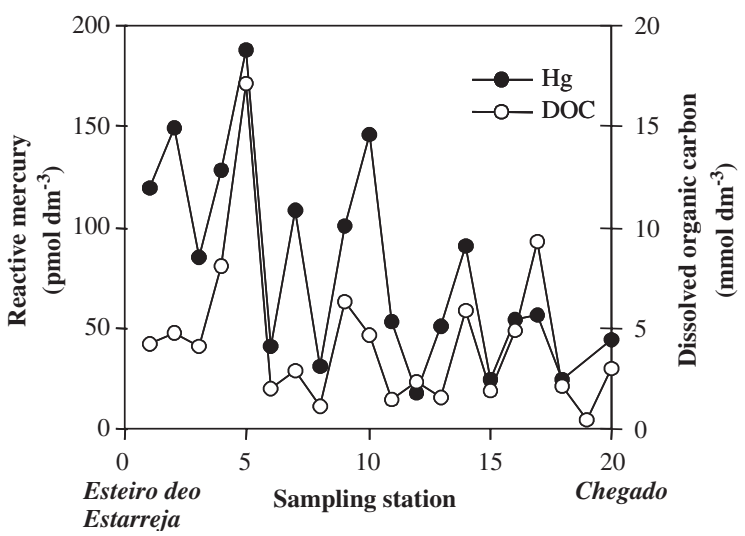

Fig. 6 - Reactive mercury (pmol dm ${ }^{-3}$ ) and dissolved organic carbon concentrations $\left(\mathrm{mmol} \mathrm{dm}{ }^{-3}\right)$ in pore waters as a function of the sampling station.

to iron oxide forms, only few studies have shown the relationship between mercury and iron oxides in the field (Matty and Long, 1995).

\subsubsection{Methylmercury production}

In Largo do Laranjo, methylmercury was detected only in one sample and its concentration represented less than $0.1 \%$ of total mercury. This local showed a small redox potential $(22 \mathrm{mV})$, indicating that mercury methylation is more favoured in suboxic conditions than in the presence of oxygen, as mentioned by Jackson (1998).

\subsubsection{Mercury in pore waters}

The organic ligands present in pore waters seem to play an important role, because a positive correlation $(r=0.690)$ was observed between reactive mercury and dissolved organic carbon (Fig. 6). A poorer correlation was obtained for total dissolved mercury $(r=0.452)$. The metal interactions between solid and liquid phases were evaluated by the distribution coefficient $\left(K_{\mathrm{D}}\right.$, $\left[\mathrm{nmol} \mathrm{Hg} \mathrm{g}^{-1}\right] /\left[\mathrm{nmol} \mathrm{Hg} \mathrm{dm}^{-3}\right]$ ) (Benoit et al., 1999), calculated as the ratio between molar concentrations of

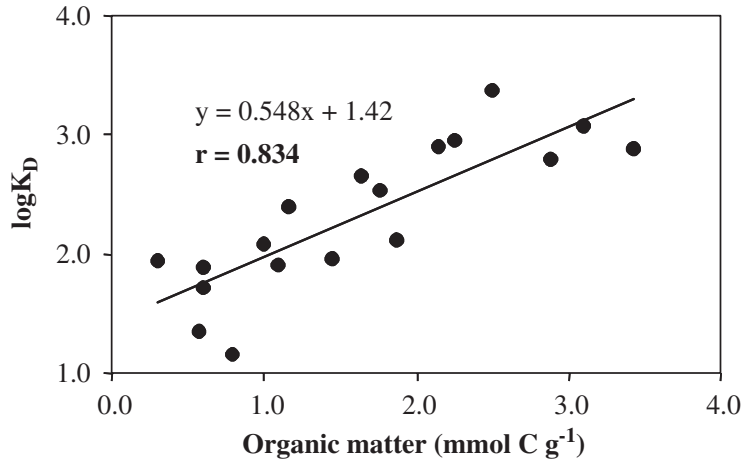

Fig. 7 - Relationship encountered in Largo do Laranjo surface sediments between $\log K_{D}$ (solid sediment/pore water distribution coefficient for mercury) and the organic carbon content $\left(\mathrm{mmol} \mathrm{g}^{-1}\right)$.

total mercury in solid sediments and of reactive mercury in pore water, and ranged from 14 to $24 \times 10^{2} \mathrm{dm}^{3} \mathrm{~g}^{-1}$. Besides, the $K_{D}$ values were positively correlated to organic carbon content in solids $(r=0.834)$ (Fig. 7), reinforcing the importance of organic matter on mercury partition in sediments.

\subsubsection{Estimation of mercury export from the pore waters to} the water column

The diffusion first Fick law allows the estimation of the diffusive fluxes (J) across water-sediment interface, by constructing a linear gradient of the solute concentration $(C)$ in pore water at the $0-0.5 \mathrm{~cm}$ layer $(\mathrm{Z})$ :

$J=-\phi D_{\text {sed }}(\partial C / \partial Z)$,

where $\phi$ is the porosity calculated as the ratio between water volume and the volume of the corresponding sediment portion, $D_{\text {sed }}$ is the whole sediment diffusion coefficient defined as $D_{\text {sed }}=D_{\text {sea water }} / \theta^{2}, \theta$ is the tortuosity estimated by the empirical relationship $\theta^{2}=1-\ln \phi^{2}$ (Boudreau, 1999) and $(\partial C / \partial Z)$ is the concentration gradient across the sediment-water interface. In Largo do Laranjo, the $D_{\text {sed }}$ varied between $1.8 \times 10^{-10}$ and $3.4 \times 10^{-10} \mathrm{~m}^{2} \mathrm{~s}^{-1}$, which is in accordance with the general value of $10^{-10} \mathrm{~m}^{2} \mathrm{~s}^{-1}$ for heavy metal ions and complexes (Li and Gregory, 1974).

The diffusion fluxes were determined for reactive and nonreactive mercury. The mercury concentrations were determined in the water column after considering the existence of a linear gradient of mercury concentrations from low to high tide. After dividing Largo do Laranjo in four zones (Fig. 1), the estimated fluxes for reactive mercury ranged between -0.013 and $0.67 \mathrm{nmol} \mathrm{Hg} \mathrm{m}^{-2}(12 \mathrm{~h})^{-1}$, as represented in Fig. 8, the highest values being found in zones A and B due to mercuryenriched pore waters. The reactive mercury fluxes were a small fraction of the total mercury fluxes, however, they can be significant in zones far away from the discharge point, representing almost $30 \%$ of the total. In terms of non-reactive mercury, the estimated fluxes ranged between 0.11 and $15 \mathrm{nmol} \mathrm{Hg} \mathrm{m} \mathrm{m}^{-2}(12 \mathrm{~h})^{-1}$, these fluxes being an order of magnitude higher than the ones related to reactive mercury. However, both mercury species show a similar behaviour. 


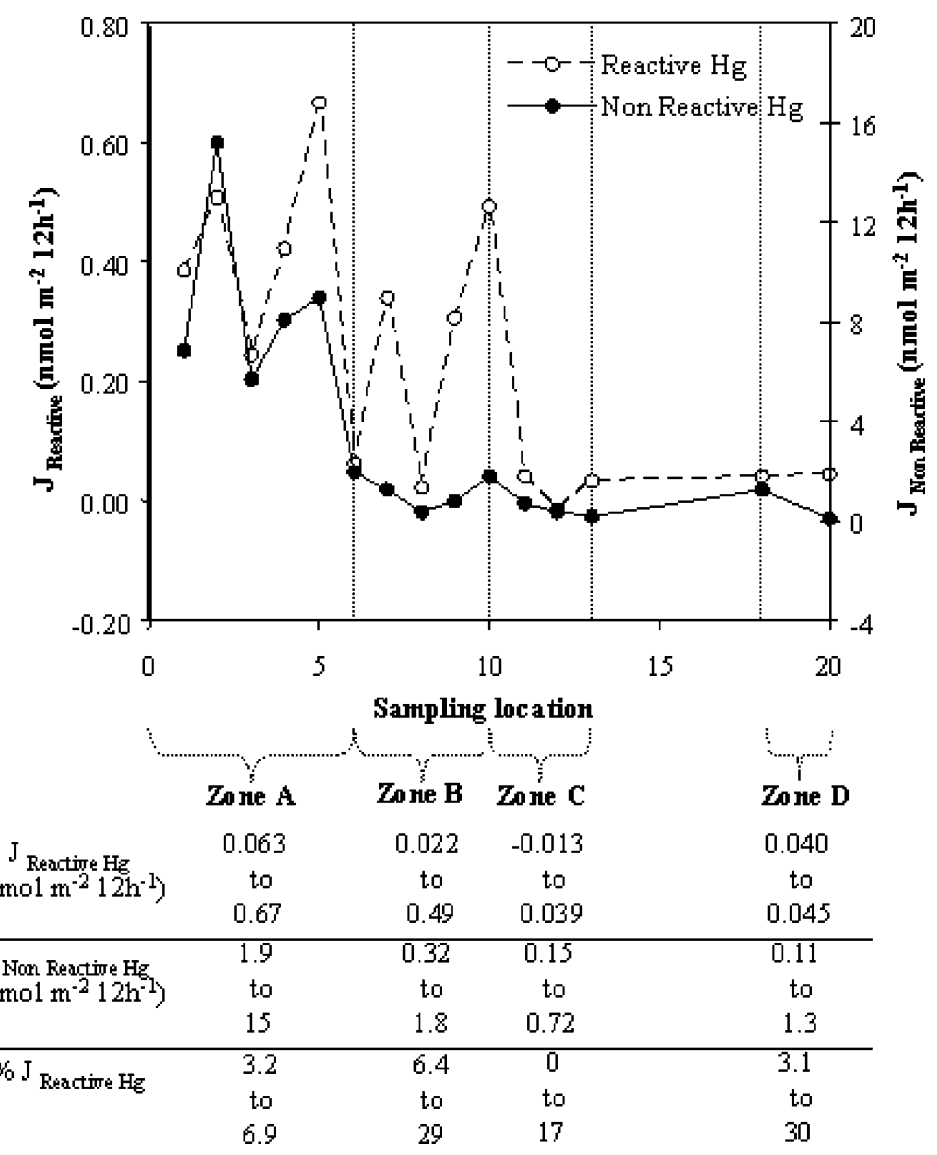

Fig. 8 - Estimation of the reactive and non-reactive mercury fluxes $\left(\mathrm{nmol} \mathrm{m}^{-2}(12 \mathrm{~h})^{-1}\right)$ from the pore waters to the water column, as well as the percentage of the reactive mercury flux, determined for the various sampling sites located on Largo do Laranjo.

Table 1 - Quantities of reactive and non-reactive mercury (nmol m${ }^{-2}(12 \mathrm{~h})^{-1}$ and $\mu \mathrm{mol} \mathrm{m}^{-2}(12 \mathrm{~h})^{-1}$, respectively) present in the Largo do Laranjo water column and estimation of the pore waters contribution to the enrichment of the water column (\%)

\begin{tabular}{|c|c|c|c|c|}
\hline & Zone A & Zone B & Zone C & Zone D \\
\hline \multicolumn{5}{|l|}{ Mercury present in water column } \\
\hline Reactive $\mathrm{Hg}\left(\mathrm{nmol} \mathrm{m}{ }^{-2}\left(12 \mathrm{~h}^{-1}\right)\right)$ & 394 & 396 & 318 & 150 \\
\hline Non-reactive $\mathrm{Hg}\left(\mu \mathrm{mol} \mathrm{m}{ }^{-2}\left(12 \mathrm{~h}^{-1}\right)\right)$ & 2.99 & 3.35 & 2.18 & 2.34 \\
\hline \multicolumn{5}{|c|}{ Contribution of pore waters to enrichment of water column } \\
\hline Reactive $\mathrm{Hg}(\%)$ & $0.016-0.17$ & $0.006-0.12$ & $0-0.012$ & $0.027-0.030$ \\
\hline Non-reactive Hg (\%) & $0.064-0.50$ & $0.010-0.054$ & $0.007-0.033$ & $0.005-0.056$ \\
\hline
\end{tabular}

Mercury fluxes were not determined in locals $14,15,16$ and 17 , because these locals were not strictly important, not being subjected to direct mercury discharge.

In order to evaluate the contribution of pore waters to the enrichment of the overlying water column, mercury was calculated in this compartment by the product of the mercury concentration determined in the water column $\left(\mathrm{nmol} \mathrm{dm}^{-3}\right)$ and water volume $\left(\mathrm{dm}^{3}\right)$ per area unit $\left(\mathrm{m}^{2}\right)$. The water volume was determined taking into account the variation in the water column height observed in a tidal cycle. This varies between 1.0 and $1.5 \mathrm{~m}$ at low and high tides, respectively. These calculations were carried out for reactive and non-reactive mercury, as shown in Table 1. The former varies between 150 and $396 \mathrm{nmol} \mathrm{m}^{-2}(12 \mathrm{~h})^{-1}$, the highest values being found in zones A, B and C, all of them with the same order of magnitude. In terms of non-reactive mercury, similar values were determined in all areas, varying between 2.2 and $3.4 \mu \mathrm{mol} \mathrm{m}{ }^{-2}(12 \mathrm{~h})^{-1}$.

Taking into account these values, in Largo do Laranjo, the pore waters contribute only $0.2 \%$ to the enrichment of the overlying water with respect to reactive mercury. In terms of non-reactive mercury, pore waters can have a more significant role. However, the contribution does not exceed $0.5 \%$, reinforcing the idea that mercury in Largo do Laranjo surface 
sediments is in a stable form, limiting its flux to the water column.

\section{Conclusions}

The results of this study show that mercury concentrations in upper sediments and the water column were significant, in spite of reductions in the emissions in the last years in Largo do Laranjo. The incorporation of anthropogenic mercury in sediments is not a simple function of distance to the source, but depends on sediment characteristics.

In the upper layers of sediment, mercury is retained by iron oxyhydroxides, as well as organic matter. However, it can be released to the pore waters due to the iron oxyhydroxides reduction and the organic matter decay, causing an equilibrium between the solid and liquid phases.

As the mercury concentrations in pore waters largely exceed the values encountered in the water column, mercury remobilisation from sediments to water column can occur. However, the reactive and non-reactive mercury present in pore waters can contribute only $0.2 \%$ and $0.5 \%$ to the water column enrichment, respectively. Moreover, the mercury diffusion from pore waters is more significant in the areas near the mercury source.

In overall conclusion, the mercury diffusion from pore waters does not contribute significantly to the dissolved mercury distribution in the overlying water column in Largo do Laranjo, demonstrating that the mercury cycling between the water column and the surface sediments is not significant.

\section{R E F E R E N C E S}

Bellucci, L.G., Frignani, M., Paolucci, D., Ravanelli, M., 2002. Distribution of heavy metals in sediments of the Venice Lagoon: the role of the industrial area. Sci. Total Environ. 295, $35-49$.

Benoit, J.M., Gilmour, C.C., Mason, R.P., Heyes, A., 1999. Sulphide controls on mercury speciation and bioavailability to methylating bacteria in sediment pore waters. Environ. Sci. Technol. 33, 951-957.

Boudreau, B.P., 1999. Metals and models: diagenetic modeling in freshwater lacustrine sediments. J. Paleolimnol. 22, 227-251.

Cossa, D., Gobeil, C., 2000. Mercury speciation in the lower St. Lawrence Estuary. Can. J. Fish. Aquat. Sci. 57, 138-147.

Diego, A., Tseng, C.M., Stoichev, T., Amouroux, D., Donard, O.F.X., 1998. Interferences during mercury speciation determination by volatilization, cryofocusing, gas chromatography and atomic absorption spectroscopy: comparative study between hydride generation and ethylation techniques. J. Anal. Atomic Spectrom. 13, 623-629.

Fitzgerald, W.F., Mason, R.P., 1997. Biogeochemical cycling of mercury in the marine environment. In: Sigel, A., Sigel, H. (Eds.), Metal Ions in Biological Systems, vol. 34. Mercury and its Effects on Environment and Biology, pp. 53-111.

Gill, G.A., Bruland, K.W., 1990. Mercury speciation in surface freshwater systems in California and other areas. Environ. Sci. Technol. 24, 1392-1400.
Hong, J., Förstner, U., Calmano, W., 1994. Effects of redox processes on acid-producing potential and metal mobility in sediments. In: Hamelink, J.L., Landrum, P.F., Bergman, H.L., Benson, W.H. (Eds.), Bioavailability: Physical, Chemical and Biological Interactions. Lewis Publishers, USA, pp. 119-143.

Jackson, T.A., 1998. Mercury in aquatic ecosystems. In: Langston, W.J., Bebianno, M.J. (Eds.), Metal Metabolism in Aquatic Environments. Chapman \& Hall, London, pp. 77-138.

Kennish, M.J., 1998. Trace metal-sediment dynamics in estuaries: pollution assessment. In: Ware, G.W. (Ed.), Review Environmental Contamination Toxicology, vol. 155. Springer, Berlin, pp. 69-110.

Kramer, K.J.M., Brockmann, U.H., Warwick, R.M., 1994. In: Brockmann, U.H., Kramer, K.J.M., Warwick, R.M. (Eds.), Tidal Estuaries: Manual of Sampling and Analytical Procedures. A.A. Balkema Publishers, Netherlands, pp. 145-147.

Lacerda, L.D., Gonçalves, G.O., 2001. Mercury distribution and speciation in waters of the coastal lagoons of Rio de Janeiro, SE Brazil. Mar. Chem. 76, 47-58.

Li, Y.H., Gregory, S., 1974. Diffusion of ions in sea water in deepsea sediments. Geochim. Cosmochim. Acta 38, 703-714.

Lucas, M.F., Caldeira, M.T., Hall, A., Duarte, A.C., Lima, C., 1986. Distribution of mercury in the sediments and fishes of the lagoon of Aveiro, Portugal. Water Sci. Technol. 18 (4-5), 141-148.

Martino, M., Turner, A., Nimmo, M., Millward, G.E., 2002. Resuspension, reactivity and recycling of trace metals in the Mersey Estuary, UK. Mar. Chem. 77, 171-186.

Matty, J.M., Long, D.T., 1995. Early diagenesis of mercury in the Laurentian Great Lakes. J. Great Lakes Res. 21, 574-586.

Monterroso, P., Abreu, S.N., Pereira, E., Vale, C., Duarte, A.C., 2003. Estimation of $\mathrm{Cu}, \mathrm{Cd}$ and $\mathrm{Hg}$ transported by plankton from a contaminated area (Ria de Aveiro). Acta Oecol. 24, 351-357.

Mucci, A., Lucotte, M., Montgomery, S., Plourde, Y., Pichet, P., VanTra, H., 1995. Mercury remobilization from flooded soils in a hydroelectric reservoir of northern Quebec, La Grande-2: results of a soil resuspension experiment. Can. J Fish. Aquat. Sci. 52, 2507-2517.

Paraquetti, H.H.M., Ayres, G.A., Almeida, M.D., Molisani, M.M., Lacerda, L.D., 2004. Mercury distribution, speciation and flux in the Sepetiba Bay tributaries, SE Brazil. Water Res. 38, 1439-1448.

Pereira, M.E., Duarte, A.C., Millward, G.E., Abreu, S.N., Vale, C., 1998a. An estimation of industrial mercury stored in sediments of a confined area of the lagoon of Aveiro (Portugal). Water Sci. Technol. 37 (6-7), 125-130.

Pereira, M.E., Duarte, A.C., Millward, G.E., Vale, C., Abreu, S.N., 1998b. Tidal export of particulate mercury from the most contaminated area of Aveiro's Lagoon, Portugal. Sci. Total Environ. 213, 157-163.

Ramalhosa, E., Monterroso, P., Abreu, S., Pereira, E., Vale, C., Duarte, A., 2001a. Storage and export of mercury from a contaminated bay (Ria de Aveiro, Portugal). Wetlands Ecol. Manage. 9, 311-316.

Ramalhosa, E., Segade, S.R., Pereira, E., Vale, C., Duarte, A., 2001b. Microwave-assisted extraction for methylmercury determination in sediments by high performance liquid chromatography-cold vapour-atomic fluorescence spectrometry. J. Anal. Atomic Spectrom. 16, 643-647.

Sundby, B., 1994. Sediment-water exchange processes. In: Hamelink, J.L., Landrum, P.F., Bergman, H.L., Benson, W.H. (Eds.), Bioavailability: Physical, Chemical and Biological Interactions. Lewis Publishers, USA, pp. 143-149. 